\title{
Effect of Internet Addiction on Mental Health of Adolescent Boys and Girls
}

\author{
Gayatri Raina $^{1}$, Sonia Bhatt ${ }^{2}$ \\ ${ }^{1}$ Associate Professor, Department of Applied Psychology, Gurugram University, Sector-50, Gurugram, \\ Haryana. \\ ${ }^{2}$ Research Scholar, Dept of Psychology, Himachal Pradesh University, Summer Hill, Shimla, Himachal \\ Pradesh.
}

Corresponding author: Gayatri Raina

Email-gayatri.raina3@gmail.com

\begin{abstract}
Background: This study evaluates the relationship between Internet Addiction and mental health among adolescent student of three Army Public Schools located at Lucknow Cantt.

Methodology: 513 participants (260 boys and 253 girls) in the study were 9th and 11th grade students in the age range of 14 to 18 years. Internet Addiction Test (IAT) developed by Kimberly Young (1996) was used to measure the addiction of Internet among adolescent and the Mental Health Inventory (MHI-38) designed by Davies, Sherbourne, Peterson and Ware (1998) was used to assess the multi-dimensional nature of psychological distress and psychological well-being, including: Anxiety, Depression, Loss of Behavioural/Emotional Control, General Positive Affect, Emotional Ties and Life Satisfaction. t-test was carried out to determine the significance of difference between boys and girls on Internet addiction and six domains of mental health. Correlation analysis was carried out to identify the relationship between Internet Addiction and mental health separately for boys and girls.

Results: The results have indicated that boys had significantly higher Internet Addiction as compared to girls. Boys had significantly higher levels of anxiety and loss of emotional/behavioural control whereas girls significantly outscored boys on the dimensions of depression, general positive affect, emotional ties and life satisfaction. Among boys Internet Addiction had a significant positive correlation with anxiety, depression and loss of behavioural/ emotional control whereas it had a significant negative effect on general positive affect, emotional ties and life satisfaction. Among girls Internet Addiction had a significant positive correlation with depression, loss of emotional/ behavioural control whereas it had a significant negative correlation with general positive affect, emotional ties and life satisfaction.

Conclusion: Internet addiction has a significant impact on the mental health of adolescent boys and girls and further studies in this regard are warranted.
\end{abstract}

Keywords: Internet addiction, Mental Health, Adolescent Boys, Adolescent Girls

$$
\text { (Paper received }-13^{\text {th }} \text { January 2021, Peer review completed }-15^{\text {th }} \text { March 2021) }
$$

(Accepted $-18^{\text {th }}$ March 2021)

\section{INTRODUCTION}

Today we are living in a revolutionary world of dots and coms and, within seconds, several new inventions are happening around the globe, media technology being one of them. Media technology has changed our lives giving us the freedom to perform activities from the comfort zone of our homes. The evolving technology has a strong impact on an individual's life especially teenagers as they are vulnerable to change. The invention of the cell phone, appearance of computers, laptops, and Internet communication has become a vital link in communicating with others. It has become inseparable part of our life and it is everywhere and 
it is impossible to escape from them. Twenty first century is the world of technology and Internet has grown leaps and bounds from the time of its origin to the present times globally.

The use of the Internet has grown rapidly in the past two decades, especially amongst the adolescent population. As the Internet becomes pervasive and increasingly indispensable in young individuals' lives, Internet addiction has also emerged as a serious public health issue due to its close relationships with adolescent health problems, risk behaviors, and social functioning problems.

There are 4.1 billion Internet users in the world as of December 2018. This is compared to 3.9 billion Internet users in mid-2018 and about 3.7 billion Internet users in late 2017.Asia has the most Internet users of all continents accounting for 49 per cent of all Internet users (down from about 50 per cent in 2017 and up from about 48 per cent mid-2018). Europe is a runner up with 16.8 per cent of all Internet users. China has the most Internet users of all countries. At over 802 million Internet users at the time of writing this, China currently accounts for almost 20 per cent of Internet users worldwide. It is trailed by India, with over 500 million Internet users.

There are several factors that may contribute to Internet addiction. These factors are related to both one's social environment and psychological state [1]. In specific, Internet addiction is often firstly observed in young age, during which one is highly curious and wants to experiment with new technology. The continuous increase in the number of single-parent families and the increasing number of parents who work most hours of the day may be partly responsible for children's unsupervised overuse of the Internet [2]. In addition, many youngsters make excessive Internet use due to factors related to following new trends (e.g., latest online game or application) in their social environment [3]. Internet anonymity, faceless communication and the option to adopt a different identity tend to support people with such disorders to feel more secure and express themselves better online than offline, and this may result in Internet addiction [4].

Adolescent have the highest level of Internet use of any age group. Estimates of usage by adolescents range from 93 per cent to 97 per cent, with more than half going online everyday [5-6]. Of teenagers surveyed by the Pew Internet \& American Life Project, 84 per cent said they owned at least one personal media device, including a laptop or desktop computer, a Personal Digital Assistant (PDA), or a cellular telephone, and 44 per cent reported owning two or more such devices [7]. There are age-related differences in how people use the Internet, with younger users being more likely than adults to communicate online, to create or read a blog, to download music, to play online games, and to "surf" the Web for fun [8-9]. Overall, teenagers use the Internet's social elements more often than adults [10].

The idea of mental health is complex and comprehensive. This term consists of two words 'Mental' and 'Health'. Health generally means sound condition or well-being or freedom from diseases. It is mostly related to physical health of the individual. A person is said to be physically healthy when his body is functioning well and he is free from pains and troubles. Mental health is as important as physical health to an individual's holistic development. It refers to a person's, emotional, social and psychological well-being. Mental health has been mentioned as the ability of the person to balance one's desires and aspirations, to cope with the stresses of life and to make psychosocial adjustment. Mental health is a term used to describe how well the individual is adjusted to the demands and opportunities of life. Moreover, mental health is not only the absence of depression, anxiety, or any mental disorder. It is an individual's ability to enjoy life, bounce back after difficult experiences, achieve balance, adapt to adversity, feel safe and secure and achieve one's potential.

Several studies have found a relationship between mental health and Internet addiction, Internet usage and Internet attitude among undergraduate university and schools' students. Mental pressure is increasing day by day, especially at the adolescent students. Unrest and frustration are occurring in almost all the spheres of their lives leading to imbalanced personalities in society and thus hampering its progress. No individual can personally and socially be well adjusted without being mentally healthy. The mentally healthy person has developed attitudes in relation to himself and his environment which has lifted him above childishness 'in thought and behavior. Mentally healthy person accept responsibility for their actions. They don't look for excuses for their behavior and satisfied in life. Most mental health professionals believe that there are a variety of contributing factors to the onset of a mental illness. Studies have found that there are physical, social, environmental and psychological causes for mental illness [11]. It is becoming clear through research 
that many of these conditions are caused by a combination of biological, psychological, and environmental factors.

The major objectives of the present study were -

- To measure and compare Internet Addiction and Mental health among adolescent boys and girls.

- To measure and compare the effect of Internet Addiction on Mental health of adolescent boys and girls.

\section{METHODOLOGY}

\section{Instruments Used}

Internet Addiction Test: Internet Addiction Test (IAT) developed by Kimberly Young (1996) is a reliable and valid measure of addictive use of Internet. This test was used to measure the addiction of the Internet among adolescent. It is a 20-item scale covering the degree to which use of Internet disrupts everyday life (work, sleep, relationships, etc.). Each item has been scored on a 5 point likert scale. The score ranges from 20 to 100 . On the basis of the total score obtained on the test, the individual is placed into one of three categories: average online user (from 20 to 39) moderate Internet use (from 40 to 69); and excessive Internet use (from 70 to 100).The higher the score, the greater the level of addiction. The internal reliability of the scale is 0.93 [12].

Mental Health Inventory (MHI-38): The Mental Health Inventory (MHI-38) was designed by Davies, Sherbourne, Peterson and Ware in 1998. It is a 38 item measure designed to assess the multi-dimensional nature of psychological distress and psychological well-being, including: Anxiety, Depression, Loss of Behavioural/Emotional Control, General Positive Affect, Emotional Ties and Life Satisfaction. The Mental Health Inventory has a reported .93 cronbach alpha rating whereas its abbreviated version has .82 . All of the 38 items on the scale, except two, are scored on a six-point scale (range 1-6). Items 9 and 28 are the exception, each scored on a five-point scale (range 1-5). The MHI-38 has been categorized into six subscales namely Anxiety, Depression, Loss of Behavioral/Emotional Control, General Positive Affect, Emotional Ties and Life Satisfaction, which are further divided into two global scales i.e. psychological distress and psychological well- being [13].

Table 1: Item composition of the six MHI subscales included in MHI-38

\begin{tabular}{|l|l|l|l|}
\hline Subscales & Component items & Subscale directionality & $\begin{array}{l}\text { Subscale raw } \\
\text { score range }\end{array}$ \\
\hline Anxiety & $\begin{array}{l}\text { Items } 3,11,13,15,25, \\
29,32,33 \text { and } 35\end{array}$ & Higher scores = greater Anxiety & $9-54$ \\
\hline Depression & Items $9,19,30$ and 36 & $\begin{array}{l}\text { Higher scores = greater } \\
\text { Depression }\end{array}$ & $4-23$ \\
\hline $\begin{array}{l}\text { Loss of Behavioral/ } \\
\text { Emotional Control }\end{array}$ & $\begin{array}{l}\text { Items } 8,14,16,18,20, \\
21,24,27 \text { and } 28\end{array}$ & $\begin{array}{l}\text { Higher scores = greater Loss of } \\
\text { Behavioral / Emotional Control }\end{array}$ & $9-53$ \\
\hline $\begin{array}{l}\text { General Positive } \\
\text { Affect }\end{array}$ & $\begin{array}{l}\text { Items } 4,5,6,7,12,17, \\
26,31,34 \text { and 37 }\end{array}$ & $\begin{array}{l}\text { Higher scores = greater Positive } \\
\text { Affect }\end{array}$ & $10-60$ \\
\hline Emotional Ties & Items 10 and 23 & $\begin{array}{l}\text { Higher scores = stronger } \\
\text { Emotional Ties }\end{array}$ & $2-12$ \\
\hline Life Satisfaction & 1 & $\begin{array}{l}\text { Higher score=greater life } \\
\text { satisfaction }\end{array}$ & $1-6$ \\
\hline
\end{tabular}

After scoring items as indicated, items belonging to each subscale are summed to give subscale scores.

\section{Sample}

A purposive sampling approach was employed to select a total sample of 513 students. The data was collected from the three Army Public Schools located at Lucknow Cantt. The data from students was taken after obtaining permission from the school Principals to conduct the study in their respective schools. In the present study, only 2 per cent children were civilians and 98 per cent children were from army background. 
Participants, in the study were 9th and 11th grade students in the age range of 14 to 18 years. All the students of 9th and 11th grade were administered the protocol. The class strength comprised of on an average of 40 students per class. The test was administered to the students in two settings. Three sections each of 9th and 11th standard from each of the three selected schools were taken. Initially, total number of 720 students participated in the study but due to incomplete responses, incorrect responses and in certain cases nonavailability of the students in the second day of test finally only those students were retained for the final data analysis who were present on both the days of test execution, completed the test as per the instructions and had access to Internet at home. The final sample, thus, comprised of 513 students. Out of which there were 260 boys and 253 girls. Out of the final total sample of 513 adolescents 280 and 233 were from 9 th and 11th standard, respectively. The test was administered to the students during their regular school time in their respective classes in the presence of their teacher and researcher.

\section{STATISTICAL ANALYSIS}

The scores for mean, standard deviation for both Internet Addiction and six dimensions of mental health were calculated and from that T-ratios were calculated to evaluate whether or not there exists a significant difference on mean scores among adolescent boys and girls on Internet Addiction and mental health. Furthermore, correlation test was carried out to assess the effect of Internet addiction on mental health separately for boys and girls.

\section{RESULTS}

It is depicted in Table 2 that adolescent boys $(M=65.94)$ have significantly $(t=6.830, p<.05)$ scored higher on Internet Addiction as compared to adolescent girls $(\mathrm{M}=52.63)$. This indicates that boys are more addicted to Internet as compared to girls.

Table 2: Showing the Mean, Standard Deviation and t-ratio of adolescent boys and adolescent girls on the Internet Addiction and Mental Health

\begin{tabular}{|l|l|l|l|l|l|}
\hline \multirow{2}{*}{ Variables } & \multicolumn{2}{|c|}{$\begin{array}{c}\text { Adolescent Boys } \\
\text { (N= 260) }\end{array}$} & \multicolumn{2}{c|}{$\begin{array}{c}\text { Adolescent Girls } \\
\text { (N=253) }\end{array}$} & \multirow{2}{*}{ t-ratio } \\
\cline { 2 - 5 } & $\mathrm{M}$ & $\mathrm{SD}$ & $\mathrm{M}$ & $\mathrm{SD}$ & \\
\hline Internet Addiction & 65.948 & 22.2992 & 52.632 & 21.2826 & $\mathbf{6 . 8 3 0}$ \\
\hline Anxiety & 31.300 & 14.4579 & 30.736 & 8.3340 & $\mathbf{. 5 3 4}$ \\
\hline Depression & 14.620 & 6.6178 & 15.644 & 4.5888 & $\mathbf{2 . 0 1 1}$ \\
\hline $\begin{array}{l}\text { Loss of Behavioral/Emotional } \\
\text { Control }\end{array}$ & 32.696 & 10.7507 & 30.308 & 9.8477 & $\mathbf{2 . 5 9 0}^{* *}$ \\
\hline General positive affect & 32.692 & 7.9495 & 36.624 & 10.9461 & $\mathbf{4 . 5 9 6}^{* *}$ \\
\hline Emotional Ties & 6.308 & 2.1873 & 6.844 & 2.0149 & $\mathbf{2 . 8 5 0}^{*}$ \\
\hline Life Satisfaction & 3.452 & 1.3292 & 4.256 & 1.3965 & $\mathbf{6 . 5 9 4}^{* *}$ \\
\hline
\end{tabular}

Furthermore, it is clear from Table 2 that adolescent girls $(\mathrm{M}=15.64)$ significantly, $(\mathrm{t}=2.01, \mathrm{p}<.05)$ scored higher on Depression as compared to adolescent boys $(\mathrm{M}=14.62)$.

The mean and $\mathrm{t}$ - values $(\mathrm{t}=2.59, \mathrm{p}<.05)$ as shown in Table 2 reveals that adolescent boys $(\mathrm{M}=32.69)$ scored significantly higher on Loss of Behavioural/ Emotional Control as compared to adolescent girls $(M=30.30)$ which clearly shows that girls are better regulated in terms of their emotional and behavioural control as compared to boys. The mean score of adolescent girls $(\mathrm{M}=36.62)$ is significantly $(\mathrm{t}=4.5, \mathrm{p}<.05)$ higher on General Positive Affect as compared to boys $(\mathrm{M}=32.69)$ as is shown in Table 2. It depicts that girls in the present investigation had a more positive general affect as compared to boys. Likewise, the results presented in Table 2 reveal that adolescent girls $(\mathrm{M}=6.84)$ significantly $(\mathrm{t}=2.85, \mathrm{p}<.05)$ scored higher on the dimension of Emotional Ties as compared to adolescent boys $(M=6.30)$. These results reflect that girls in 
the present study have better emotional ties, interpersonal relationships and emotional attachments as compared to male adolescents. Table also signifies the significant difference on the dimension of Life Satisfaction among adolescent boys and girls. The girls $(M=4.25)$ have significantly $(t=6.59, p<.05)$ higher life satisfaction as compared to adolescent boys $(M=3.45)$.The results indicate that girls are more contended, satisfied and happy as compared to the boys.

From the above mentioned results it can be concluded that on the six dimensions of Mental Health girls have significantly outscored boys on the dimension of depression, general positive affect, emotional ties and life satisfaction, whereas boys significantly outscored girls on the dimension of Loss of Behavioural /emotional control. Results indicate that girls are significantly better on the psychological wellbeing except depression. Boys have significantly higher psychological distress in terms of loss of behavioural/emotional control.

\section{Inter-correlation of Internet Addiction and mental health among adolescent Boys}

Inter-correlation was carried out to see the effect of Internet Addiction on the mental health of the selected sample of boys. Table 3 reveals that Internet Addiction has a positive and significant correlation with anxiety $(\mathrm{r}=.711, \mathrm{p}<.01)$, depression $(\mathrm{r}=.362, \mathrm{p}<.01)$ and loss of behavioural/ emotional control $(\mathrm{r}=.377, \mathrm{p}<.01)$ which clearly shows that higher the Internet Addiction higher is the anxiety, depression and loss of behavioural/ emotional control among adolescent boys.

Furthermore, the results indicate that Internet Addiction has a negative and significant correlation with general positive effect $(r=-.366, p<.01)$, emotional ties $(r=-.262, p<.01)$ and life satisfaction $(r=-.282$, $p$ $<.01)$. It signifies that higher the Internet Addiction lesser is the general positive affect, emotional ties and life satisfaction among adolescent boys.

Table 3: Showing Correlation of Internet Addiction and six sub variables of Mental Health among Adolescent Boys

\begin{tabular}{|l|l|}
\hline Variables & $\begin{array}{l}\text { Internet } \\
\text { Addiction }\end{array}$ \\
\hline Mental Health & $0.711^{* *}$ \\
\hline Anxiety & $0.362^{* *}$ \\
\hline Depression & $0.377^{* *}$ \\
\hline Loss of Behavioral/ Emotional control & $-0.366^{* *}$ \\
\hline General Positive Affect & $-0.262^{* *}$ \\
\hline Emotional Ties & $-0.282^{* *}$ \\
\hline Life Satisfaction $\quad{ }^{*} p<0.05,{ }^{* *} p<0.01$ \\
\hline \multicolumn{2}{|l|}{}
\end{tabular}

\section{Inter-correlation of Internet Addiction and Mental Health among Girls}

It is evident from Table 4 that Internet Addiction has a positive and significant correlation with depression $(\mathrm{r}=.298, \mathrm{p}<.01)$ and loss of behavioural/ emotional control $(\mathrm{r}=.541, \mathrm{p}<.01)$ which clearly shows that higher the Internet Addiction higher is the depression and loss of behavioural/ emotional control among adolescent girls.

Table 4: Showing Correlation of Internet Addiction with six variables of Mental health among Adolescent Girls

\begin{tabular}{|l|l|}
\hline Variables & Internet Addiction \\
\hline Anxiety & 0.018 \\
\hline Depression & $0.298^{* *}$ \\
\hline Loss of Behavioural/Emotional control & $0.541^{* *}$ \\
\hline General Positive Affect & $-0.293^{* *}$ \\
\hline Emotional Ties & $-0.266^{* *}$ \\
\hline
\end{tabular}




\section{Life Satisfaction} $-0.360^{* *}$

The results as depicted in Table 4 further reveal that Internet Addiction has a negative and significant correlation with general positive effect $(r=-.293, \mathrm{p}<.01)$, emotional ties $(r=-.266, p<.01)$ and life satisfaction $(r=-.360, p<.01)$ among girls. It signifies that higher the Internet Addiction lesser is the general positive affect, emotional ties and life satisfaction among adolescent girls.

\section{DISCUSSION}

\section{Gender Differences in Internet Addiction}

One of the major findings of the present study was that the adolescent boys significantly had higher Internet Addiction than their female counterparts. The Internet is becoming increasingly influential for many people specially adolescents. Some of the empirical studies have recognized gender to be the most important factor influencing Internet addiction. As expected, male adolescents were found to have higher levels of Internet addiction than their female counterpart. This provides support to the findings of researchers [14-17] who in their respective studies reported that males were significantly higher on Internet addiction as compared to females.

There are some known causes of Internet addiction which have been reported by researchers, causes can vary by age, gender, and of course, personality. Generally, Internet addicts tend to form an emotional attachment to the on-line friends and activities they create inside their computer screens. They enjoy those aspects of the Internet which allowed them to meet, socialize, and exchange ideas with new people through highly interactive Internet applications (such as chatting, playing on-line games, or being involved with social networks). These virtual communities create a vehicle to escape from reality and seek out a means to fulfil an unmet emotional and psychological need. Men more than women enjoy interactive on-line games which draw upon power and dominance.

Moreover, research evidence indicates that men are the early adopters of the Internet [18], and the reason for the gender difference in Internet adoption is that men tend to be more interested in technology than women [19]. In one of the earliest longitudinal Internet studies, Kraut and his team [20] concluded that males used the Internet more than females even when both were provided with free access. Hence, a large gender divide existed with the percentage of males using the Internet being twice that of females; 26 per cent vs. 13 per cent respectively [18]. In general, male teenagers seem to have a higher tendency to be addicted to the Internet [21-22].

The Internet like food or drugs addictions provides the "high" and addicts become dependent on this cyberspace to feel normal. They substitute unhealthy relationships for healthy ones. They opt for temporary pleasure rather than the deeper qualities of "normal" intimate relationships. Internet addiction follows the same progressive nature of other drug addictions. Internet addicts struggle to control their behaviors, and experience despair over their constant failure to do so. Their loss of self-esteem grows, fuelling the need to escape even further into their addictive behaviors. A sense of powerlessness pervades the lives of addicts.

Boys and girls have different motivations and use the Internet differently. Boys are more likely to use the Internet for entertainment purposes [23-26]. Girls tend to use the Internet primarily for interpersonal communication [27-29]. Similar findings in Singapore and in Hong Kong suggest that these gender differences prevail over different cultures [30-31]. Thus, the risk factors for Internet addiction range from personal, social, and behavior specific factors, highlighting the multifactorial model of development of Internet addiction.

\section{Gender Differences in Mental Health}

The findings of the present research work reveal that on the six dimensions of Mental Health (namely anxiety, depression loss of behavioral/emotional control, general positive affect, emotional ties and life satisfaction) boys were significantly high on the loss of behavioral /emotional control (psychological distress). On the other hand, girls were significantly better on the general positive affect, life satisfaction and emotional ties (psychological wellbeing) but at the same time girls outscored in depression as compared to boys. 
A noteworthy finding of the present research work was that male students outscored in loss of behavioral /emotional control as compared to female students. The results are in consonance with the study of Bjorkqvist and others [32] who reported that males were more likely than females to express their aggression physically. They also showed that females tend to show their aggression in less overt and less physical ways. Gender is an important factor that is responsible for human aggression. Coie and Dodge [33] revealed that males are more aggressive than females. Buss [34] made a survey and showed that majority of murders in society are committed by men. This is the most reliable example of behavioral sex differences. It is found across many different age groups and cultures. There are empirical evidences that males are quicker to get aggressive as compared to females.

Several theories have been proposed, trying to explain this phenomenon, most of them being from social psychological theories. One of the most popular theories is of the American social psychologist Leonard Berkowitz [35]. According to him, men and women are socialized, traditionally, to carry out different social roles. Berkowitz [35] argued that a modern society teaches children that fighting is more suitable for men than to women. Folk literature and the media constantly present men, and not women, fighting. Parents buy toy guns for boys and dolls for girls. Parents are more willing to endorse and encourage the aggressive behavior of boys, and not of girls. Again and again, directly and indirectly, minors learn that men are aggressive, and women are not [36]. It may be because a large strand of research stresses the biological ('nature') reasons for behavioral problems, i.e. the development of female brains is different from male brains and this may have consequences at early ages for the observed gender gap in behavior. But 'nurture' also seems to matter. Behavioral problems may stem from both nature and nurture, but the most important determinant of behavioral skills seems to be gender: Girls tend to have much less behavioral problems at school age than their male peers [37]. Gender difference in for instance child rearing inputs may affect the way behavioral skills are produced according to one of the survey reported by Heckman [38].

Ha and Hwang [39], who state that when males and females are stressed, females are encouraged to express feelings such as sadness and to use more emotional strategies, whereas males are discouraged from expressing their feelings, and they tend to adopt distracting or aggressive strategies.

The results of the current study further demonstrated that depression was significantly more prevalent among adolescent girls than adolescent boys. Khasakhala and others [40] who conducted a cross-sectional study to determine the prevalence of depressive symptoms among adolescents revealed that the prevalence of clinically significant depressive symptoms were higher in girls than in boys. Similar results have been reported by other researchers [41-48] who showed that girls reported a higher prevalence of symptoms of depression than boys. Mental health problems affect women and men equally, but some are more common among women. A longitudinal study of the mental health of adults in Great Britain [49] reported that women were more likely to have been treated for a mental health problem than men. This could be because, when asked, women were more likely to report symptoms of common mental health problems. Depression during the teen years comes at a time of great personal change when boys and girls form their identity apart from their parents, grappling with gender issues and emerging sexuality, and make their own independent decisions for the first time in their lives [50-51].

Results of the present investigation further reveal that adolescent girls had higher general positive affect and life satisfaction as compared to adolescent boys. Questions related to positive affect or happiness and life satisfaction have been studied by ancient philosophers dating as far back as Aristotle in $350 \mathrm{BC}$. A contemporary meaning of life satisfaction is conceptualized as a cognitive, global appraisal that people make when considering their level of contentment with their life as a whole [52]. As society is seen to be the provider,the environment for well-being, individuals generally judge whether they are happy in that environment. In essence, life satisfaction is a subjective assessment of the quality of one's life [53]. Life satisfaction is a feeling of happiness and satisfaction with one's life. It may be possible that a person is satisfied with almost all domains (e.g., financial, health, marriage, education etc.) which he/she weighs as most important may positively affect life satisfaction [54]. Previous studies conducted regarding life satisfaction among adolescents have shown that most adolescents view their overall lives positively [55].

Thayer and others [56] found that women rely on social support more frequently to overcome negative moods. Similarly, although, Tkach and Lyubomirsky [57] found that men and women were equally happy, they uncovered gender differences in the use of happiness-enhancing strategies. These differences can also 
be attributed to the different domains of life satisfaction. Girls were more satisfi ed than boys in learning and family and friends, and the opposite was true in physical activities, culminating in no signifi cant difference in overall life satisfaction [58].

Montgomery [59] reported that across the vast majority of countries where surveys have been conducted, the average woman responded that they had higher life satisfaction than the average man. When tens of thousands of people in over 100 countries were asked to assess how satisfied they were with their present lives, on aggregate, women scored higher than men. It is also apparent from the findings of the present study that girls were significantly better in emotional ties as compared to boys. The results of the study are in congruence with Tannen [60] who claimed that women express emotions, share personal feelings, relate and listen empathetically to others, whereas men engage in competitive joking and assertive speech to win control of the conversation. In addition, some evidence suggested that boys were more likely to stress their independence from others, whereas girls were more likely to emphasize their relatedness with others [61].

\section{Effect of Internet Addiction on the Mental Health of adolescent Boys}

In the present study it has been found that out of six sub variables of mental health, Internet addiction was significantly and positively related to anxiety, depression and loss of behavioral/emotional control and negatively related to general positive affect, emotional ties and life satisfaction among adolescent boys. The result indicates that higher Internet addiction among adolescents leads to poor mental health among them in the state of Uttar Pradesh.

One of the worst effects of Internet addiction is anxiety and depression. Increase in using Internet leads to a number of problems, one of them is Internet anxiety among boys [62]. There exists a positive and significant correlation between the level of anxiety and Internet addiction [62]. Similar findings have been reported by others [63] that the males who suffer from Internet addiction may experience increased levels of anxiety as a withdrawal symptom as well as comorbid depression. Those suffering from anxiety may start using the Internet excessively as a coping mechanism to relieve dysphoric mood.

As per Global Peace Index [64], about 2.8 million youth in the age group of 12-17 years have at least one major depressive episode. It has been found that Internet addiction is associated with depression and adolescent's experience depression when they are prohibited from playing online games. Along the same lines, depression has been found to increase among Internet-addicted. Similar results have been reported by many authors [65-70] who reported that Internet addiction was typically characterized by psychomotor agitation, anxiety, craving, depression, hostility, substance experience, preoccupation, loss of control, withdrawal, impairment of function, reduced decision-making ability and constant online surfing despite negative effects on social and psychological welfare.

It has also been reported that addicted students are more likely to have low psychological well-being [71]. Internet addiction has emerged to be the potential problem in adolescents. From the reported negative consequences, it appears that Internet addiction can have a variety of detrimental outcomes for young people that may require professional intervention. The use of Internet may serve as an escape from the feelings of depression, but over use of Internet can make things worse. Internet addiction further leads to isolation, stress, and loneliness.

Another important finding of the study shows that Internet Addiction is negatively and significantly related to General Positive Affect, Emotional Ties and Life Satisfaction among adolescent boys. Pratarelli, Brown and Johnson [72] argued that increased Internet addiction was associated with feelings of isolation, which were mutually reinforcing. A study on the USA children revealed that children using the Internet have a very limited dimension of friendship [73]. They also spend less time talking with their families, experiencing more daily stress, and feeling lonelier and depressed. Regarding the impact on psychosocial well-being, Internet addiction was found to be associated with subjective distress and social impairment. Weiser [74] found a negative association between Internet addiction and general wellbeing.

These findings are in accordance with the previous studies stating that there is a strong association between general positive affect, emotional ties, life satisfaction and Internet addiction among males [75]. The result of the study are also in congruence with others [76] who investigated the association of affective temperament profiles and emotional and behavioural characteristics with Internet addiction among high schoolmale students. According to the findings, there was a relation between the Internet addiction and 
affective temperament profiles, especially with anxious temperament. Furthermore, emotional and behavioural problems were more frequent in adolescents who had Internet addiction.

Gedam and others [77] estimated the prevalence, understood the pattern, and determined the association between psychopathology and Internet addiction among undergraduates. Significant association was found between psychopathology and Internet addiction. Male gender, login status, emotional ties, and psychological distress were found to be important predictors of Internet addiction among students. Eichenberg and others [78] conducted a study on attachment and emotional ties and found that participants with insecure attachment style showed a higher tendency to Internet addiction as compared with securely attached participants.

Life satisfaction is one of the several aspects of positive mental health. People who are satisfied with their life are able to make them engaged to identify the purposes of life. If their satisfaction level is hampered by the addiction to Internet, it is difficult for them to engage in activities that sustain their life and make it purposeful. So, the assumption that Internet addicts would have poor life satisfaction, which, in turn, would lead to decreased life engagement, is supported by the present findings. This might happen because the use of Internet has significantly affected everyone's life, specifically adolescents and young adults, a generation who has forgotten the line between online and real world interaction. The existence of addictive Internet use may exert detrimental effects on their lives. All these things impair people's cognitive judgment of satisfaction because people's quality of life tends to be a direct function of their evaluations of important life domains such as social support, leisure activities, and standard of living of overall life and being online for long time destructs people to focus on valued goals of their life. Thus, their life satisfaction level becomes poor and they find difficulty to be engaged in life.

\section{Effect of Internet Addiction on the Mental Health of adolescent Girls}

Another important finding of the present study was that Internet addictionwas significantly and positively correlated withdepression and loss of behavioural/emotional control.

Internet addiction and depression were found to be significantly associated among adolescents girls [79]. Numerous studies conducted outside India among diverse population groups in various countries have also found depression to be associated with the risk of Internet addiction [63, 80-81]. Depressive patients might find online communication easier and less intimidating than real-world communication owing to anonymity, absence of nonverbal cues and physical presence. These factors help them overcome their interpersonal difficulties, often seen in depression. Those suffering from depression may have a tendency to use the internet excessively to relieve low mood and escape the feelings of guilt and hopelessness.

These finding are supported by the findings of Rabadi and others [82] who found that Internet addiction was completely associated with depression, stress, and anxiety among girls. The analysis of the study results suggests that the association of the two conditions is multifaceted, and shows the effect of Internet addiction in developing other psychological symptoms. All the studies observed that Internet addiction increases the risk of complications whether they were mental disorders or addictive disorders. Internet addiction and depression occur together approximately twice as frequently as would be predicted by chance alone. Comorbid social media addiction and depression are a major clinical challenge as the outcomes of both conditions are worsened by the other. Due to the rapid development and popularization of the Internet in Asia, the prevalence of Internet addiction in the region has grown rapidly [83]. The results of research have also confirmed the relationship between Internet addiction and depressive emotions in Asian adolescents specially females [84].

Similar results have been reported by Yang, Fu and Chen [85] in their recent study that depressive emotions can lead to subsequent unhealthy behaviour such as Internet addiction, especially in female adolescent. Therefore, studies that examine the relationships among depression, health related behaviour, and Internet addiction in female adolescents are warranted.

The results of the study further revealed that Internet addiction has a negative impact on the general positive affect, emotional ties and life satisfaction among girls. Internet Addiction is an important factor threatening the mental health of people, especially female students. It could lead to increased depression and social isolation, also behavioural problems, weakening social ties and decreasing the quality of the relationship with family and friends. Although the exact cause of the relationship between mental health and Internet 
Addiction among females is not known, yet it seems that female students have Internet to fill their loneliness, which could be because of psychological problems.

The result of the study corroborates with the study of Wang and others [86] who reported that Internet Addiction is a disorder of impulse control in using the Internet, that has negative effects on the performance of daily life, behavioral problems, social and emotional ties, family relationships, and emotional stability. The results of the present study showed a statistically significant relationship between lower general positive affect and Internet addiction among females. Similarly, such significant relationship was reported by a study conducted among students of Guilan University of Medical Sciences. In this study, the average general positive affect of students at risk of high dependence on the Internet was less than students, who showed normal use of the Internet [87]. In a study conducted by Frangos, similar results were seen to that of the current study [88].

\section{REFERENCES}

1. Hur MH. Demographic, habitual, and socioeconomic determinants of Internet addiction disorder: an empirical study of Korean teenagers. Cyberpsychol Behav 2006;9(5):514-25.

2. Kuss DJ, Griffiths MD, Binder JF. Internet addiction in students: Prevalence and risk factors. Comp Hum Behav 2013;29(3):959-66.

3. Kuss DJ. Internet addiction: the problem and treatment. Addicta: Turkish J Addiction 2016;3(2):185-92.

4. Amichai-Hamburger Y, Wainapel G, Fox S. " On the Internet no one knows I'm an introvert": Extroversion, neuroticism, and Internet interaction. Cyberpsychol Behav 2002;5(2):125-8.

5. Cenameri M. Internet, child and adolescence social development. Mediterr J Soc Sci 2013;4(2):571-4.

6. Weinstein A, Lejoyeux M. Internet addiction or excessive internet use. Am J Drug Alcohol Abuse 2010;36(5):277-83.

7. Lenhart A, Madden M. Teen content creators and consumers. Washington, DC: Pew Internet \& American Life Project; 2005,

8. Howard PE, Rainie L, Jones S. Days and nights on the Internet: The impact of a diffusing technology. Amer Behav Scientist 2001;45(3):383-404.

9. Christakis DA. Internet addiction: a 21 st century epidemic?. BMC Med 2010;8(1):1-3.

10. Enagandula R, Singh S, Adgaonkar GW, Subramanyam AA, Kamath RM. Study of internet addiction in children with attention-deficit hyperactivity disorder and normal control. Industr Psychiatry J 2018;27(1):1109.

11. Bhandari PM, Neupane D, Rijal S, Thapa K, Mishra SR, Poudyal AK. Sleep quality, internet addiction and depressive symptoms among undergraduate students in Nepal. BMC Psychiatry 2017;17(1):1-8.

12. Alavi SS. Psychometric properties of Young internet addiction test. Int J Behav Sci 2010;4(3):183-9.

13. Davies CA, Spence JC, Vandelanotte C, Caperchione CM, Mummery WK. Meta-analysis of internetdelivered interventions to increase physical activity levels. International Journal of Behav Nutr Physical Activity 2012;9(1):1-3.

14. Sharma $\mathrm{P}$, Bharati A, De Sousa A, Shah N. Internet addiction and its association with psychopathology: a study in school children from Mumbai, India. Natl J Community Med 2016;7(1):2-5.

15. Rehman A, Shafi H, Rizvi T. Internet addiction and psychological well-being among youth of Kashmir. Int $\mathrm{J}$ Indian Psychol 2016;3(3):6-11.

16. Arthanari S, Khalique N, Ansari MA, Faizi N. Prevalence \& determinants of Internet Addiction among Indian adolescents. Indian J Commun Health 2017;29(1):89-95.

17. Shao YJ, Zheng T, Wang YQ, Liu L, Chen Y, Yao YS. Internet addiction detection rate among college students in the People's Republic of China: a meta-analysis. Child Adolesc Psychiatry Ment Health 2018;12(1):1-10.

18. Pavlik, J., New Media Technology : Cultural and Commercial Perspectives, Needham Heights, MA: Allyn \& Bacon, 1996.

19. Shashanni L. Gender differences in computer attitudes and use among college students. J Educ Comput Res 1997;16(1):37-51.

20. Kraut R, Lundmark V, Patterson M, Kiesler S, Mukopadhyahy T, Sherlis W. Internet paradox: A social technology that reduces social involvement and psychological well-being ? Amer Psychol 1998;53:1017-31.

21. Deng YX, Hu M, Hu GQ, Wang LS, Sun ZQ. An investigation on the prevalence of internet addiction disorder in middle school students of Hunan province. Zhonghua liu xing bing xue za zhi 2007;28(5):445-8.

22. Soh PC, Chew KW, Koay KY, Ang PH. Parents vs peers' influence on teenagers' Internet addiction and risky online activities. Telemat Informat 2018;35(1):225-36.

23. Wolfradt U, Doll J. Motives of adolescents to use the Internet as a function of personality traits, personal and social factors. J Educ Comput Res 2001;24(1):13-27.

24. Palesh O, Saltzman K, Koopman C. Internet use and attitudes towards illicit internet use behavior in a sample of Russian college students. Cyberpsychol Behav 2004;7(5):553-8. 
25. Park SM, Park YA, Lee HW, Jung HY, Lee JY, Choi JS. The effects of behavioral inhibition/approach system as predictors of Internet addiction in adolescents. Personal Individ Diff 2013;54(1):7-11.

26. Dalbudak E, Evren C, Aldemir S, Coskun KS, Ugurlu H, Yildirim FG. Relationship of internet addiction severity with depression, anxiety, and alexithymia, temperament and character in university students. Cyberpsychol Behav Soc Network 2013;16(4):272-8.

27. Colley A, Comber C. Age and Gender Differences in Computer Use and Attitudes among Secondary School Students: What Has Changed?. Educ Res 2003;45(2):155-9.

28. Aydm B, San SV. Internet addiction among adolescents: the role of self-esteem. Proc Soc Behav Sci 2011;15:3500-5.

29. Madell D, Muncer S. Internet Communication: An Activity That Appeals to Shy and Socially Phobic People? Cyberpsychol Behav 2004;9(1):618-22.

30. Teo T, Lim V. Gender differences in internet usage and task preferences. Behav Inform Technol 2000;19(4): 283-95.

31. Ho RC, Zhang MW, Tsang TY, Toh AH, Pan F, Lu Y, Cheng C, Yip PS, Lam LT, Lai CM, Watanabe H. The association between internet addiction and psychiatric co-morbidity: a meta-analysis. BMC Psychiatry 2014;14(1).

32. Karnes MR, Baldwin TR, Barnett EJ, Bensen MJ, Bjorkquist D, Brusic SA, Buffer JJ, Custer RL, DeVore PW, Dugger WE, Dyrenfurth MJ. Technology education in prospect: Perceptions, change, and the survival of the profession. J Technol Stud 1999;25(1):11-35.

33. Cole SH, Hooley JM. Clinical and personality correlates of MMO gaming: Anxiety and absorption in problematic internet use. Soc Sci Computer Rev 2013;31(4):424-36.

34. J Kuss D, D Griffiths M, Karila L, Billieux J. Internet addiction: A systematic review of epidemiological research for the last decade. Curr Pharmaceut Design 2014;20(25):4026-52.

35. Berkowitz L. Whatever happened to the frustration-aggression hypothesis?. Amer Behav Scientist 1978;21(5):691-708.

36. Berkowitz L. Frustrations, appraisals, and aversively stimulated aggression. Aggress Behav 1988;14(1):3-11.

37. Heckman JJ. The case for investing in disadvantaged young children. CESifo DICE Report 2008;6(2):3-8.

38. Tremblay J, Bertrand K, Blanchette-Martin N, Rush B, Savard AC, L'espérance N, Demers-Lessard G, Genois R. Estimation of needs for addiction services: A youth model. J Stud Alcohol Drugs 2019;(s18):64-75.

39. Ha YM, Hwang WJ. Gender differences in internet addiction associated with psychological health indicators among adolescents using a national web-based survey. Int J Ment Health Addict 2014;12(5):660-9.

40. Khasakhala L, Ndetei DM, Mutiso V, Mbwayo A, Mathai M. The prevalence of depressive symptoms among adolescents in Nairobi public secondary schools: association with perceived maladaptive parenting behaviour. Afr J Psychiatry 2012;12(2):106-13.

41. Sun Y, Wilkinson JS. Parenting style, personality traits, and interpersonal relationships: A model of prediction of internet addiction. Int J Commun 2020;14:23-30.

42. Essau CA. Comorbidity of addictive problems: Assessment and treatment implications. In Adolescent Addiction 2020;(pp.291-317). Academic Press.

43. Rotondi AJ, Sinkule J, Haas GL, Spring MB, Litschge CM, Newhill CE, Ganguli R, Anderson CM. Designing websites for persons with cognitive deficits: Design and usability of a psychoeducational intervention for persons with severe mental illness. Psychol Serv 2007;4(3):202.

44. Verma N, Jain M, Roy P. Assessment of magnitude and grades of depression among adolescents in Raipur City, India. Int Res J Med Sci 2014;2(5):10-3.

45. Mohanraj R, Subbaiah K. Prevalence of depressive symptoms among urban adolescents in South India. J Indian Assoc Child Adolesc Ment Health 2010;1:33-43.

46. Short MB, Black L, Smith AH, Wetterneck CT, Wells DE. A review of Internet pornography use research: Methodology and content from the past 10 years. Cyberpsychol Behav Soc Network 2012;15(1):13-23.

47. Jain AV, Bickham D. Adolescent health literacy and the Internet: challenges and opportunities. Curr Opin Pediatr 2014;26(4):435-9.

48. Nocera TR, Dahlen ER. Dark triad personality traits in cyber aggression among college students. Viol Victims 2020;35(4):524-38.

49. National Statistics Omnibus Survey. Individuals accessing the internet, National Statistics Omnibus Survey, April; 2005.

50. Shaffer HJ, Hall MN, Bilt JV. "Computer addiction": a critical consideration. Am J Orthopsychiatry 2000;70(2):162-8.

51. Taymur I, Budak E, Demirci H, Akdağ HA, Güngör BB, Özdel K. A study of the relationship between internet addiction, psychopathology and dysfunctional beliefs. Comp Hum Behav 2016;61:532-6.

52. Chou WP, Ko CH, Kaufman EA, Crowell SE, Hsiao RC, Wang PW, Lin JJ, Yen CF. Association of stress coping strategies with Internet addiction in college students: The moderating effect of depression. Compr Psychiatry 2015;62:27-33.

53. Diener E, Wirtz D, Tov W, Kim-Prieto C, Choi D, Oishi S. New well-being measures: Short scales to assess flourishing and positive and negative feelings. Soc Indicators Res 2010;97:143-56.

54. Diener E. Subjective well-being. Psychol Bull 1984;95:542-75.

55. Shek DT, Yu L. Adolescent internet addiction in Hong Kong: prevalence, change, and correlates. J Pediatr Adolesc Gynecol 2016;29(1):S22-30. 
56. Moretta T, Buodo G. Autonomic stress reactivity and craving in individuals with problematic Internet use. PLoS One 2018;13(1):e0190951.

57. Tkach EN, Sitnikova EV. Distinctive personality traits of present-day adolescents-active users of social media. Human Soc Sci Rev 2019;7(6):1008-15.

58. Casas JA, Ruiz-Olivares R, Ortega-Ruiz R. Validation of the internet and social networking experiences questionnaire in Spanish adolescents. Int J Clin Health Psychol 2013;13(1):40-8.

59. Daine K, Hawton K, Singaravelu V, Stewart A, Simkin S, Montgomery P. The power of the web: a systematic review of studies of the influence of the internet on self-harm and suicide in young people. PloS One 2013;8(10):e77555.

60. Tannen D, Trester AM, editors. Discourse 2.0: Language and new media. Georgetown University Press; 2013.

61. De Morentin JI, Cortés A, Medrano C, Apodaca P. Internet use and parental mediation: A cross-cultural study. Comp Educ 2014;70:212-21.

62. Nima AA, Archer T, Garcia D. The happiness-increasing strategies scales and well-being in a sample of Swedish adolescents. Int J Happiness Dev 2013;1(2):196-211.

63. Younes F, Halawi G, Jabbour H, El Osta N, Karam L, Hajj A, Rabbaa Khabbaz L. Internet addiction and relationships with insomnia, anxiety, depression, stress and self-esteem in university students: A cross-sectional designed study. PloS One 2016;11(9):e0161126.

64. Index GP. Quantifying peace and its benefits. Sydney, Australia: Institute for Economics and Peace. 2016.

65. Kandell JJ. Internet addiction on campus: The vulnerability of college students. Cyberpsychol Behav 1998;1(1):11-7.

66. Shaw LH, Gant LM. Users divided? Exploring the gender gap in Internet use. Cyberpsychol Behav 2002;5(6):517-27.

67. Cao H, Sun Y, Wan Y, Hao J, Tao F. Problematic Internet use in Chinese adolescents and its relation to psychosomatic symptoms and life satisfaction. BMC Pub Health 2011;11(1):1-8.

68. van Den Eijnden RJ, Spijkerman R, Vermulst AA, van Rooij TJ, Engels RC. Compulsive Internet use among adolescents: Bidirectional parent-child relationships. J Abnorm Child Psychol 2010;38(1):77-89.

69. Mihara S, Osaki Y, Nakayama H, Sakuma H, Ikeda M, Itani O, Kaneita Y, Kanda H, Ohida T, Higuchi S. Internet use and problematic Internet use among adolescents in Japan: A nationwide representative survey. Addict Behav Rep 2016;4:58-64.

70. Van Rooij AJ, Ferguson CJ, Van de Mheen D, Schoenmakers TM. Time to abandon Internet Addiction? Predicting problematic Internet, game, and social media use from psychosocial well-being and application use. Clin Neuropsychiatry 2017;14(1):113-21.

71. Cardak M. Psychological well-being and Internet addiction among university students. Turkish Online J Educ Technol TOJET 2013;12(3):134-41.

72. Pratarelli ME, Browne BL. Confirmatory factor analysis of Internet use and addiction. Cyberpsychol Behav 2002;5(1):53-64.

73. Severo RB, Soares JM, Affonso JP, Giusti DA, de Souza Junior AA, de Figueiredo VL, Pinheiro KA, Pontes HM. Prevalence and risk factors for internet gaming disorder. Brazil J Psychiatry 2020;42(5):532-5.

74. Weiser EB. Gender differences in Internet use patterns and Internet application preferences: A two-sample comparison. Cyberpsychol Behav 2000;3(2):167-78.

75. Alavi SS, Ferdosi M, Jannatifard F, Eslami M, Alaghemandan H, Setare M. Behavioral addiction versus substance addiction: Correspondence of psychiatric and psychological views. Int J Prev Med 2012;3(4):290-9.

76. Öztürk C, Bektas M, Ayar D, Öztornac1 BÖ, Yağc1 D. Association of personality traits and risk of internet addiction in adolescents. Asian Nurs Res 2015;9(2):120-4.

77. Gedam SR, Ghosh S, Modi L, Goyal A, Mansharamani H. Study of internet addiction: Prevalence, pattern, and psychopathology among health professional undergraduates. Indian J Soc Psychiatry 2017;33(4):305-11.

78. Eichenberg C. Internet message boards for suicidal people: A typology of users. Cyberpsychol Behav 2008;11(1):107-13.

79. Goel D, Subramanyam A, Kamath R. A study on the prevalence of internet addiction and its association with psychopathology in Indian adolescents. Indian J Psychiatry 2013;55(2):140-5.

80. Choi M, Park S, Cha S. Relationships of mental health and internet use in Korean adolescents. Arch Psychiatr Nurs 2017;31(6):566-71.

81. Kawabe K, Horiuchi F, Ochi M, Oka Y, Ueno SI. Internet addiction: Prevalence and relation with mental states in adolescents. Psychiatr Clin Neurosci 2016;70(9):405-12.

82. Tomaszek K, Muchacka-Cymerman A. Sex differences in the relationship between student school burnout and problematic Internet use among adolescents. Int J Environ Res Pub Health 2019;16(21):4107.

83. Chen YF, Peng SS. University students' Internet use and its relationships with academic performance, interpersonal relationships, psychosocial adjustment, and self-evaluation. Cyberpsychol Behav 2008;11(4):4679.

84. Chang FC, Chiu CH, Miao NF, Chen PH, Lee CM, Chiang JT, Pan YC. The relationship between parental mediation and Internet addiction among adolescents, and the association with cyberbullying and depression. Compr Psychiatry 2015;57:21-8.

85. Yang J, Guo Y, Du X, Jiang Y, Wang W, Xiao D, Wang T, Lu C, Guo L. Association between problematic internet use and sleep disturbance among adolescents: the role of the child's sex. Int J Environ Res Pub Health 2018;15(12):2682. 
86. Wang L, Luo J, Gao W, Kong J. The effect of Internet use on adolescents' lifestyles: A national survey. Comp Hum Behav 2012;28(6):2007-13.

87. Cao H, Sun Y, Wan Y, Hao J, Tao F. Problematic Internet use in Chinese adolescents and its relation to psychosomatic symptoms and life satisfaction. BMC Pub Health 2011;11(1).

88. Frangos CC, Frangos CC, Sotiropoulos I. Problematic internet use among Greek university students: an ordinal logistic regression with risk factors of negative psychological beliefs, pornographic sites, and online games. Cyberpsychol Behav Soc Network 2011;14(1-2):51-8.

$* * * * * * * * * * * * * * * * * * * * * * * * * * * * * * * * * * * *$

Acknowledgements - Nil

Conflict of Interest - Nil

Funding - Nil 